\title{
Author Correction: NADPH oxidase subunit NOXO1 is a target for emphysema treatment in COPD
}

Michael Seimetz (1), Natascha Sommer (D), Mariola Bednorz, Oleg Pak, Christine Veith, Stefan Hadzic (i),

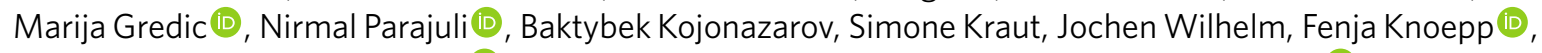
Ingrid Henneke, Alexandra Pichl(D), Zeki I. Kanbagli, Susan Scheibe, Athanasios Fysikopoulos (1), Cheng-Yu Wu (D), Walter Klepetko, Peter Jaksch (10), Christina Eichstaedt (1D), Ekkehard Grünig, Katrin Hinderhofer (1D, Miklós Geiszt (1), Niklas Müller, Flavia Rezende, Giulia Buchmann (1), Ilka Wittig (D), Matthias Hecker (D), Andreas Hecker (D), Winfried Padberg (10, Peter Dorfmüller (D), Stefan Gattenlöhner, Claus F. Vogelmeier, Andreas Günther (D), Srikanth Karnati (D), Eveline Baumgart-Vogt (1), Ralph T. Schermuly (D), Hossein A. Ghofrani (D), Werner Seeger (D), Katrin Schröder (1), Friedrich Grimminger (D), Ralf P. Brandes (1D) and Norbert Weissmann (1)

Correction to: Nature Metabolism https://doi.org/10.1038/s42255-020-0215-8, published online 8 June 2020.

In the version of this article initially published, author Eveline Baumgart-Vogt had affiliation number 15; the correct affiliation number is 14. The error has been corrected in the HTML and PDF versions of the article. 